TI 2007-017/1

Tinbergen Institute Discussion Paper

Derived Measurement in

Macroeconomics:

Two Approaches for Measuring the NAIRU Considered

\author{
Peter Rodenburg
}




\section{Tinbergen Institute}

The Tinbergen Institute is the institute for economic research of the Erasmus Universiteit Rotterdam, Universiteit van Amsterdam, and Vrije Universiteit Amsterdam.

Tinbergen Institute Amsterdam

Roetersstraat 31

1018 WB Amsterdam

The Netherlands

Tel.: $\quad+31(0) 205513500$

Fax: $\quad+31(0) 205513555$

Tinbergen Institute Rotterdam

Burg. Oudlaan 50

3062 PA Rotterdam

The Netherlands

Tel.: $\quad+31(0) 104088900$

Fax: $\quad+31(0) 104089031$

Most TI discussion papers can be downloaded at http:/ /www.tinbergen.nl. 


\title{
Derived Measurement in Macroeconomics: Two Approaches for Measuring the NAIRU considered
}

\author{
Peter Rodenburg* \\ Faculty of Economics and Econometrics \\ and Faculty of European Studies \\ University of Amsterdam \\ Spuistraat 134 \\ 1012 VB Amsterdam \\ The Netherlands \\ Tel: 0031 20-525 4660 \\ E-mail: P.Rodenburg@uva.nl \\ http://home.medewerker.uva.nl/p.rodenburg/
}

Abstract:

This paper investigates two different procedures for the measurement of the NAIRU; one based on structural modeling while the other is a statistical approach using Vector Auto Regression (VAR)-models. Both measurement procedures are assessed by confronting them with the dominant theory of measurement, the Representation Theory of Measurement, which states that for sound measurement a strict isomorphism (strict one-toone mapping) is needed between variations in the phenomenon (the NAIRU) and numbers.

The paper argues that shifts of the Phillips-curve are not a problem for the structural approach to measurement of the NAIRU, as the NAIRU itself is a time-varying concept. It is however, the impossibility to identify the exact shape of the Phillips-curve that causes problems of multiple empirical, relational forms and hence non-unique isomorphic mappings for measurement. While VAR-models are being accused of being 'atheoretical macroeconometrics' in the literature, the Wold decomposition theorem applied to the VAR brings out a stable correspondence between variance of the phenomenon (the NAIRU) and numbers and turns the set of equations into an isomorphic mapping that can serve as a useful foundation for the construction of a measuring instrument.

Keywords: NAIRU, Phillips curve, VAR-models, Measurement in macroeconomics

JEL-classification: $\mathrm{B}, \mathrm{E}$,

\footnotetext{
* I would like to thank the Massimo Giuliodori, Mary Morgan, Marcel Boumans and Harro Maas for their helpful comments and suggestions.
} 


\section{$1 \quad$ Introduction}

The NAIRU (Non-Accelerating Inflation Rate of Unemployment) refers to an unemployment rate where inflation tends to be stable and is nowadays considered as an important and useful indicator for policy makers in a variety of ways. For example, deviations from the NAIRU indicate inflationary pressures in the economy or can be used for estimating the output gap. It is sometimes taken as a measure for slackness of the labour market or used for assessing the cyclical component of unemployment. Economists have therefore put a lot of effort into measuring this concept and dozens of studies on this topic can be found. In particular, the OECD gave a strong impetus to measurement of the NAIRU. For these reasons, the NAIRU became - in spite of lasting controversies among theorists and methodologists - accepted as textbook economics, and its measurement became, in its relatively short lifespan, a classic case of measurement in macroeconomics.

The structural approach to measurement of the NAIRU is based on modeling the Phillips curve relation. In the 1960s, the Phillips curve was widely regarded as a representation of a causal relation between unemployment and inflation, and economists claimed that the Phillips curve could provide a reliable instrument for policy purposes and measurement. Due to the empirical instability that the Phillips curve revealed over the last decades, the deterministic interpretation of the Phillips curve has been relaxed. Contemporary economists now take the Phillips curve as a structural relationship without clear causal content from which we yet can derive measures of the NAIRU. Since we can no longer interpret the Phillips curve as a causal relation, and derived measurement of the NAIRU turned out to be complicated, other ways of measuring the NAIRU have been pursued; in particular 'non-causal' ways. This latter approach involves the use of statistical techniques, such as Structural Vector Auto Regression (VAR) techniques, which are based on correlation rather than causation.

The aim of this paper is twofold: i) to explore measurement of the NAIRU as a case of derived measurement from an invariant regularity (the Phillips curve); and ii) to contrast the structural ('causal') approach used to measure the NAIRU with the 'statistical' approach and so to see which provides satisfactory measurements.

This paper proceeds as follows. Section 2 discusses the Phillips curve and the theory and concept of the NAIRU. Since the concept of the NAIRU is historically and conceptually closely related to that of the Natural Rate of Unemployment, this latter concept is discussed in this section as well. Section 3 analyses the structural procedures for the measurement of the NAIRU. Section 4 questions whether the Phillips curve can be 
understood as an invariant, change-relating generalization and discusses the measurement problems associated with the structural approach to measurement of the NAIRU. In Section 5 VAR models are discussed as a representative of the 'non-causal', statistical approach, while in Section 6, is analysed whether VAR models provide satisfactory measuring instruments for the NAIRU. Finally conclusions are drawn in Section 7.

\section{The Phillips curve and the concepts of the NAIRU and the Natural Rate of Unemployment}

\subsection{The Phillips curve}

In the 1950s, a discussion arose in Great Britain about whether inflation there was caused by cost-push or demand-pull factors. The rise of import prices could initiate a wage-price spiral and so cause (cost-push) inflation. On the other hand, (demand pull) inflation could arise as a result of money wage increases in tight labour markets. Phillips (1958) wanted to distinguish between these types of inflation, and he conjectured that there was a causal relation between unemployment and inflation (Wulwick, 1989: 173). Phillips used British time-series data of the rates of change of money wages and unemployment from 18611957, which he broke down into three periods (1861-1913, 1913-1948 and 1948-1957).

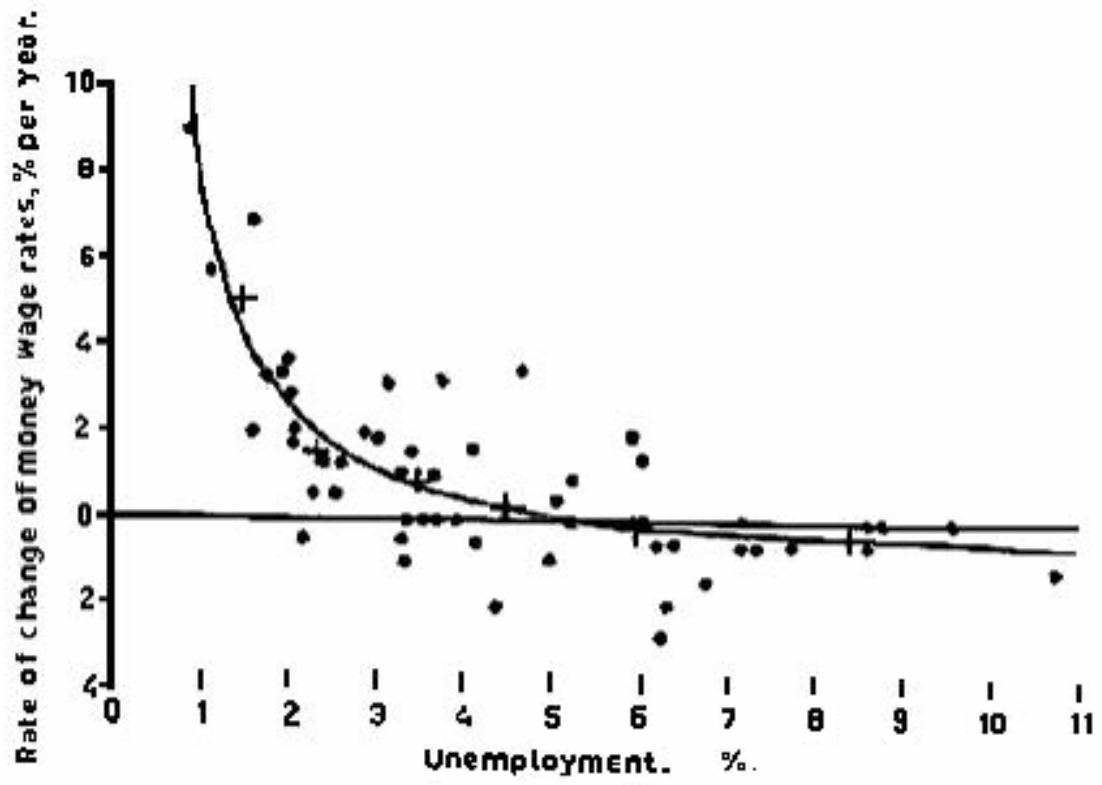

Fig.1.1861 - 1913

Figure 1: Phillips curve

Source: Phillips, 1958: 285. 
Philips fitted an empirical curve to a statistical scatter diagram of the data of the first period (1861-1913), and compared the latter periods with the first. The 1861-1913 curve that Phillips fitted was non-linear and negatively inclined, indicating an inverse relationship between unemployment and the rate of change of money wages. The curve featured stationary wage increases at an unemployment rate of $5 \frac{1}{2}$ percent and, when successive years were connected, counter-clockwise cyclical loops due to trade cycles. According to Phillips, in the period 1861-1957, there were "6 $1 / 2$ fairly regular trade cycles with an average period of about 8 years" (1958: 285). Phillips accounted for the counter-cyclical loops by breaking down the data for each completed cycle. To plot the curve, Phillips used a crude, data grouping technique known as the 'double-averaging procedure'1 (Wulwick, 1989: 175-176). Phillips formalized the curve as:

$$
\dot{w}+a=b u^{-c},
$$

where $\dot{w}$ is the growth rate of wages, $u$ the unemployment rate and $a, b$ and $c$ are parameters, and $c>0 .^{2}$ The Phillips curve thus expressed wage increases simply in a direct relationship with unemployment:

$$
\dot{w}_{t}=f\left(u_{t}\right) \quad \text { with } \quad f^{\prime}<0 \text { and } \quad f^{\prime \prime}>0 \text {. }
$$

Once introduced, the Phillips curve soon became the leading framework of macroeconomic analysis, and rapidly superseded the then dominant IS/LM model. Whereas the IS/LM model was concerned with one policy target, output, the Phillips curve implicitly related two important economic policy targets, unemployment and wage increase (later modified and replaced by inflation). These dual economic policy targets seemed to be connected by what appeared to be a simple causal relation represented by the Phillips curve itself: that is, low unemployment rates 'cause' inflation. This element was missing in Keynesian theory, and the most important contribution of the Phillips curve was perhaps the recognition that wage inflation could coexist with a considerable amount of unemployment, which

\footnotetext{
${ }^{1}$ In this technique, the horizontal axis of the scatter diagram is divided into 'convenient' intervals, and a curve is drawn through the average of each interval (indicated by the crosses in Figure 1).

${ }^{2}$ In his seminal paper, Phillips formalized the curve as: $y+a=b x^{c}$, with $y$ as the rate of change of the money wage, and $x$ the percentage unemployment. For reasons of consistency with more recent literature, the rewritten more common notation is used here.
} 
undermined the Keynesian ideal of full employment without inflation as the major goal of government policy. In this way, the Phillips curve revealed restrictions on the viability of economic policies that were absent in the IS/LM model. The trade-off aspect of policy targets became apparent after Samuelson and Solow (1960) presented the Phillips curve as a policy menu for governments. Thereby, the Phillips curve was used to clarify the discussion about full employment and how to get there, by providing operational definitions of full employment in terms of unemployment and inflation in the first place. And, given the fact that the Phillips curve was considered as a stable relation that could be measured empirically, theoretical discussions about the exact slope of both the IS and LM curve seemed to have lost their relevance. In addition, the Phillips curve provided an empirically-based way to relax the troubling assumption of fixed prices in the IS/LM model. As a consequence of these novel insights, the Phillips curve itself became the focal point of theoretical and policy discussions, and the attention of economists shifted away from the question of how to derive the appropriate economic policy from the theoretical IS/LM model to discussions about the exact shape of the Phillips curve and a theoretical underpinning of its existence.

\subsection{The Natural Rate of Unemployment and the NAIRU}

The term 'Natural Rate of Unemployment' (hereafter NRU) was coined by Milton Friedman in his 1967 Presidential Address to the American Economic Association (Friedman 1968). Friedman and Phelps (1967) dispute the existence of a trade-off between unemployment and inflation in the long run. In the long run, they argue, the economy tends to an equilibrium unemployment rate - the NRU - that is determined entirely by real factors. Friedman described this unemployment rate as the unemployment rate:

\footnotetext{
"that would be ground out by the Walrasian system of general equilibrium equations, provided that there is embedded in them the actual structural characteristics of the labour and commodity markets, including market imperfections, stochastic variability in demands and supplies, the costs of gathering information about job vacancies and labor availabilities, the costs of mobility, and so on" (Friedman, 1968: 8).
}

Friedman considers the structural and institutional arrangement of the labour market as the cause of natural unemployment. Economies with different structural and institutional arrangements of the labour market will therefore have different NRUs. 
Friedman claims to use the term 'natural' in the same way as Wicksell used his 'natural rate of interest': to separate real shocks from monetary shocks (Friedman, 1968:8). ${ }^{3}$ Friedman suggests that actual unemployment can be decomposed into a temporary and a permanent component. The temporary component of unemployment is caused by monetary factors. In the absence of monetary (inflationary) caused unemployment, the remaining unemployment, the natural rate, is permanent. Natural unemployment appears to be a sort of equilibrium search unemployment.

Consistent with this line of reasoning, Friedman argues that the unemployment rate cannot remain below NRU levels. When unemployment is pushed below the NRU level (for example because the government launches a monetary and fiscal expansion in order to reduce unemployment), the economy moves along the Phillips curve and inflation starts to increase. Workers endowed with rational expectations will realize that their real wage has dropped as prices go up and will reduce their labour supply, and unemployment will go up until the NRU is reached again. The economy has now returned to the original unemployment rate, but at a higher rate of inflation. This point lies on a new Phillips curve, above the original one. Friedman's unemployment dynamics suggests that below-NRU levels are not sustainable and invoked the idea of a long-run Phillips curve that is vertically sloped at the NRU.

The NAIRU is a concept that resembles the NRU closely. Modigliani and Papademos (1975) were the first to refer to the existence of a NIRU (Non-Inflationary Rate of Unemployment). Later Tobin (1980) transformed this concept into NAIRU: the NonAccelerating Inflation Rate of Unemployment. ${ }^{4}$ Tobin defines the NAIRU as:

"the unemployment rate at which the inflation-increasing effects of the excess-demand markets just balances the inflation-decreasing impacts of the excess-supply markets" (Tobin, 1997: 8).

The NAIRU is thus considered as the unemployment rate that is compatible with a stable, non-increasing rate of inflation. It is therefore the unemployment rate at the intersection of the empirical Phillips curve and the horizontal, $u$-axis (see Figure 2).

\footnotetext{
${ }^{3}$ The term natural rate of unemployment does not therefore seem to be very well chosen, as it does not adequately reflect the idea of distinguishing between real and monetary-caused unemployment. In addition, as Layard et al. (1991) argue, it smacks of inevitability whereas the determinants of the natural rate themselves are partly institutional and therefore not inevitable.

${ }^{4}$ The name NAIRU also seems not well chosen. It is often argued that the name gets a derivative wrong and that a more accurate term would be non-increasing inflation rate of unemployment.
} 


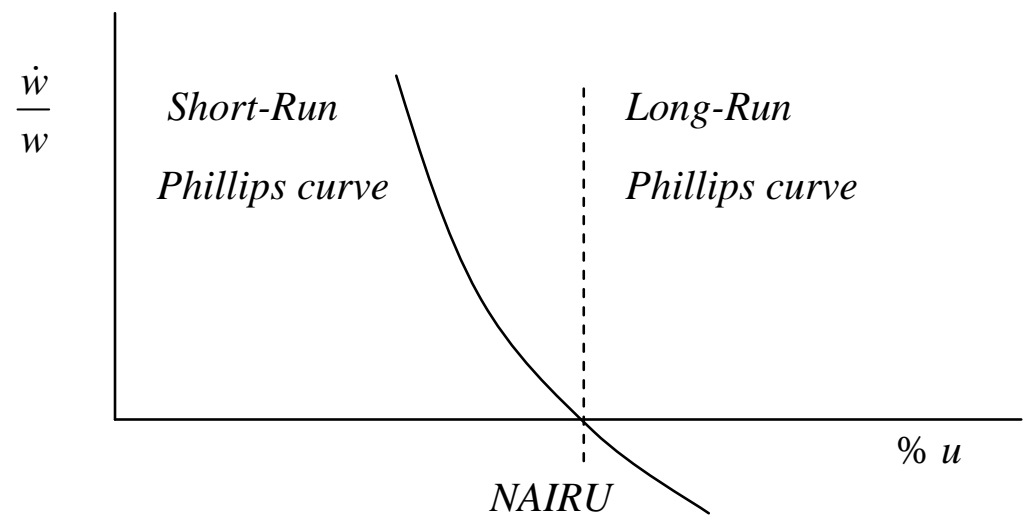

Figure 2: Short- and Long-Run Phillips curve and the NAIRU

The distinctions between the NRU and the NAIRU are small and subtle, and in recent publications the differences between the NAIRU and NRU have become even more blurred when economists started to distinguish between different kinds of NAIRUs, most notably a short-run and long-run NAIRU. ${ }^{6}$ In this paper, we will refer to the NAIRU as a long-run phenomenon only. Probably most economists cannot tell the difference between the NRU and the NAIRU, and take them to be more or less the same thing. In particular, monetarists argue that the NAIRU is just another name for the NRU. However, Keynesians and critics of monetarism, like Tobin, stress that they are definitely distinct concepts.

According to Tobin (1997), three essential features make the NAIRU different from the NRU. In the first place, the NAIRU is a not an equilibrium concept. In contrast with Friedman, who adopts a Walrasian general equilibrium framework in which markets clear by instantaneous prices adjustments, the NAIRU is clearly a disequilibrium concept. ${ }^{7}$ The theory of the NAIRU characterizes markets by simultaneous excess supply and excess demand at prevailing prices. The market is considered as a "never-ceasing inter-sectoral flux of microeconomic demands and supplies" (Tobin, 1997: 9), i.e. a nearly infinite

\footnotetext{
5 The OECD (Richardson et al., 2000: 8), for example, distinguish between:

i) The NAIRU: defined as the equilibrium rate towards which unemployment converges in the absence of temporary supply influences, once the dynamic adjustment of inflation is completed.

ii) The short-term NAIRU: defined as the amount of unemployment consistent with stabilizing the inflation rate at its current level in the next period.

iii) The long-term equilibrium rate (akin to the NRU): corresponding to a long-term steady state, once the NAIRU has fully adjusted to all supply and policy influences, including those having long-lasting effects.

${ }^{6}$ Some authors, like Cross (1995), argue that, as a consequence of the instability of the Phillips curve, and amendments to the concepts of the NRU and the NAIRU, the NRU and NAIRU became such troublesome concepts that they should better be rejected altogether on empirical grounds. Especially the further distinctions into long- and short-run NRUs and NAIRUs, have made the hypothesis untestable and immune to refutation. According to Cross, the Duhem-Quine problem - that hypotheses can be rescued from refutation by suitable amendments of auxiliary hypothesis - arises here (Cross, 1995).

7 Tobin stresses that the whole purpose of the NAIRU concept was "to escape the normative equilibrium connotations of the natural rate" (Tobin, 1997: 7-8).
} 
number of submarkets, each being out of equilibrium. For labour markets, excess demand and supply can be observed by the simultaneous occurrence of unemployment and vacancies. Secondly, as a consequence of this approach: "The NAIRU could not be modelled as a single economy-wide market or representative agent" (Tobin, 1997: 8-9). Unlike the NRU, which can be seen as a microeconomic concept, as it is based on rational search behaviour of individual agents, the NAIRU is a macroeconomic concept that has no counterpart in microeconomics. Thus the two concepts are theoretically different. The NAIRU is a Keynesian concept, whereas the NRU fits the Monetarists and New Classical paradigm.

The third distinction, and, for the measurement of the NAIRU, the most important one, follows from the above. Since the determinants of the NRU are the institutional arrangements of labour markets, it follows that each nationally-arranged labour market has its own NRU and that, provided there are no changes in these institutional arrangements, these NRUs must be constant. Changes in the NRU are only possible in the (medium) long run after institutional changes in the labour market. The NAIRU, on the other hand, is clearly a time-varying concept: "The NAIRU varies from time to time as the relationships between unemployment, vacancies and wage changes vary, and as the dispersion of excess demands and supplies across markets changes." (Tobin, 1997, i). Thus, for our purpose of measurement, this is the most relevant distinction to keep in mind: the NAIRU allows for variability, while the NRU is constant in the short term.

\section{Measurement of the NAIRU: The structural approach}

In attempts to measure the NAIRU, two basic approaches can be distinguished: the structural approach, and the statistical approach. ${ }^{8}$ Structural methods involve the specification of the wage- and price-determining relationship, and are - in contradiction with Tobin's conception of the NAIRU - most often based on some underlying rational expectations theory of agents' (firms' and trade unions') behaviour. The outcome of these agents' behaviour is the empirical unemployment-inflation relation: the Phillips curve, and the NAIRU is then the unemployment level, which is consistent with stable price and wage inflation, i.e. the level of unemployment where inflation starts to 'take off'. The most favoured way of deriving measures of the NAIRU is through the use of a structural

\footnotetext{
${ }^{8}$ A third approach for measurement of the NAIRU that is sometimes used is the reduced-form approach. It combines the two approaches, and uses both structural specification and statistical methods.
} 
approach, though recently the statistical approach has gained popularity. We will analyse the structural approach first.

The basic framework for the measurement of the NAIRU is the (simple) Phillips curve relationship. Soon after its introduction, economists made a first modification to the Phillips curve relation by replacing the rate of wage changes by the rate of price changes. The (simple) Phillips curve relationship then expresses the relation between inflation and unemployment as:

$$
\pi_{t}=-\beta\left(u_{t}-u^{*}\right)
$$

where $\pi_{t}$ is the actual rate of price inflation, $u_{t}$ the actual unemployment rate, $u^{*}$ the NAIRU, and $\beta$ a parameter. The term $\left(u_{t}-u^{*}\right)$ represents the deviation of the actual unemployment rate from the NAIRU, and is often referred to as the 'unemployment gap'.

However, since Friedman (1968) two other modifications have been made in the representation of the Phillips curve. First, the adaptively (backward-looking) formed expectations of inflation were replaced by rational (forward-looking) expectations. And, secondly, after the experience of the 1973 oil crisis, (exogenous) supply shocks were introduced as a cause of inflation. In the most general form, the expectations augmented Phillips-curve relation is formulated as:

$$
\pi_{t}=\pi_{t}^{e}-\beta\left(u_{t}-u^{*}\right)+\gamma X_{t}+v_{t}
$$

where, $\pi_{t}^{e}$ is expected price inflation, $X_{t}$ a regressor included to control supply shocks, $\gamma$ a parameter, and $v_{t}$ an error term. When expectations about inflation are realized, that is, when expected inflation coincides with realized inflation, thus when $\pi_{t}-\pi_{t}^{e}=0$, and in the absence of supply shocks $\left(X_{t}=0\right)$, the NAIRU $u^{*}$ will coincide with the actual unemployment rate $u_{t}$.

In more recent practice, economists follow a slightly different route. Most studies on the measurement of the NAIRU derive the NAIRU from a model of imperfect competitive bargaining that is popularized by Layard, Nickell and Jackman (1991). ${ }^{9}$ This model describes the supposed underlying price and wage bargaining process that could lead

9 Gordon $(1982,1997)$ popularized a slightly different approach in the USA. 
to wage-price spirals. Critics sometimes refer to this model as the "textbook approach", the "battle of mark-ups" model, or, as the "OECD NAIRU consensus" model, ${ }^{10}$ since the OECD frequently uses this model. The idea behind imperfect competitive bargaining is that both employers and firms have some market power, since hiring or firing workers is costly for both parties. These costs are, however, a function of the level of unemployment. In these models, firms set prices as a mark-up on expected wages and workers (unions) set wages on expected prices. Firms set prices as a mark up on expected wage $\left(p-w^{e}\right)$ as a positive function of employment. The price-setting function of firms then becomes in its most elementary form:

$$
p-w^{e}=\beta_{0}-\beta_{1} u_{t}
$$

where $p$ is $\log$ prices, $w^{e}$ is $\log$ expected wages, $u_{t}$ the actual unemployment rate. The wage-setting function of unions describes wage setting by unions as a negative relation between the unions' wage mark up $w-p^{e}$ and employment:

$$
w-p^{e}=\gamma_{0}-\gamma_{1} u_{t}
$$

where $w$ is log wages, and $p^{e}$ is log expected prices. In more extended models, additional variables are added. Usually a regressor $X_{1 t}$ is added to both the price and the wage-setting equations, which represents a vector of variables, such as an increase in labour productivity, that exogenously raises prices and/or wages. The wage-setting equation is also often extended with a vector of variables $X_{2 t}$, such as union power. So, the price setting behaviour of firms will then be:

$$
p-w^{e}=\beta_{0}-\beta_{1} u_{t}+\beta_{2} X_{1 t} .
$$

The wage-setting behaviour of unions:

$$
w-p^{e}=\gamma_{0}-\gamma_{1} u_{t}+\gamma_{2} X_{1 t}+\gamma_{3} X_{2 t}
$$

\footnotetext{
10 For example by Mitchell and Muysken (2003).
} 
For the sake of the argument, it suffices to proceed with only one regressor, $X_{1 t}$, so we will ignore $X_{2 t}$ in the remainder of this paper. A stable inflation will now occur when expectations about future prices and wages are realized, thus when the identities $p=p^{e}$ and $w=w^{e}$ hold. When expectations are not fully realized, a wage-price spiral will occur, as wage-setters try to regain the losses imposed on them by price setters, and vice versa, and inflation will start to accelerate. Therefore, equilibrium, and hence non-increasing inflation, exists at the intersection of the wage-setting and price-setting curve, creating a NAIRUlevel of unemployment of $u^{*}$ (see Figure 3).

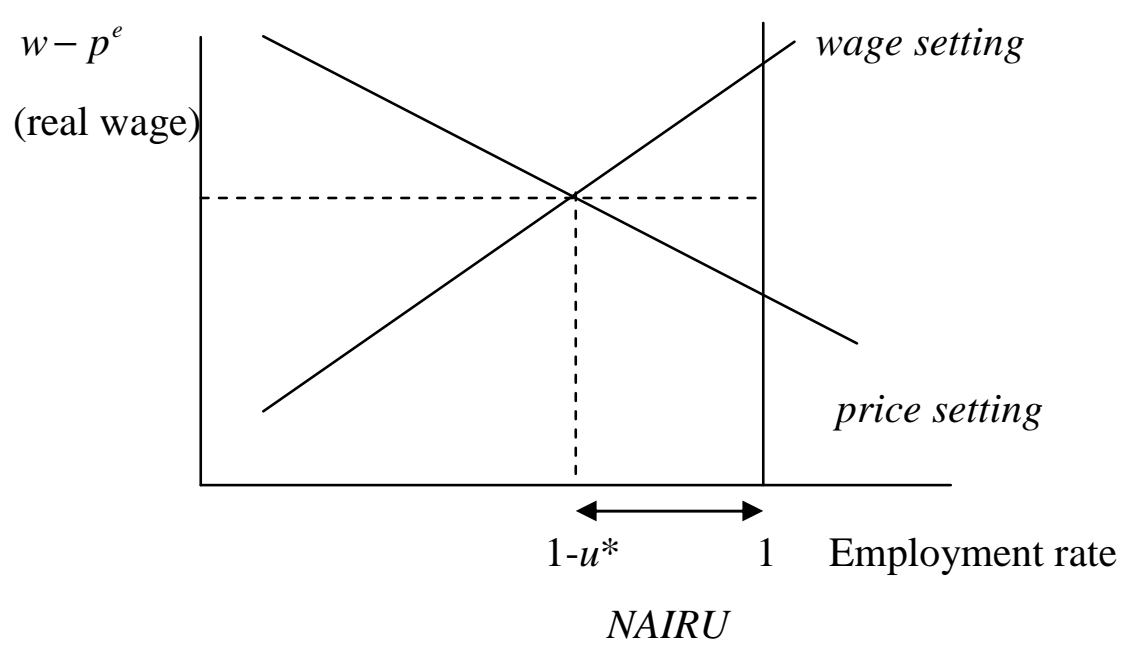

Figure 3: Price- and wage- setting equilibrium

Source: Based on Layard, Nickell and Jackman, 1991: 14.

Thus, by using this equilibrium identity, the cumbersome expectations variables cancel out and a more comprehensible equation remains. The equilibrium rate of unemployment in the simplest case is then:

$$
u^{*}=\frac{\beta_{0}+\gamma_{0}}{\beta_{1}+\gamma_{1}}
$$

which we can think of as the NAIRU. In the more elaborated case, the NAIRU becomes:

$$
u^{*}=\frac{\beta_{0}+\gamma_{0}+\left(\beta_{2}+\gamma_{2}\right) X_{1 t}}{\beta_{1}+\gamma_{1}}
$$




\section{$4 \quad$ The Phillips curve as an invariant regularity for measurement?}

Measurement deals with the assignment of numbers to objects or phenomena according to a well-described rule. In the Representational Measurement Theory - the dominant theory of measurement in the philosophy of science - measurement is defined as showing that "the structure of a set of phenomena under certain empirical operations and relations is the same as the structure of some set of numbers under corresponding arithmetical operations and relations" (Suppes, 1998). In other words, the relevant structure of the phenomenon must be mapped isomorphic (strictly one-to-one) with an arithmetical structure. ${ }^{11}$ A change in a phenomenon then necessitates a corresponding change in numbers (measures).

A wide variety of principles can be used as an isomorphic mapping for measurement (Rodenburg, 2006). According to Campbell (1928), a strategy for the measurement of unobservables is to 'derive' a quantity from a 'numerical law' in which the unobservable of interest participates, and through which it is connected to other variables that are observable (measurable). Campbell considers this as derived measurement, which he defines as "measurement by means of constants in numerical laws", where a numerical law "relates the results of measurements of two or more quantities", and "constants" refer to constant parameters in a system, such as the gas constant in the ideal gas law or the constant of gravitation in Newton's law (Campbell cited in Ellis, 1966: 54). As to the nature of this physical relation between magnitudes (variables) in the 'numerical law', Campbell argues that it "is always some kind of uniform association; it is the relation between things which are such that the presence of one is always an indication of the other" (1928: 58). A necessary conjunction of variables is thus essential. This may seem to suggest a causal law, but that stretches the point too far. Identities of the kind $m=\rho \times V$ (mass $=$ density $\mathrm{x}$ volume) also fall under 'numerical laws' according to Campbell (1928: $57)$.

Woodward (2000) provides a similar, but more sophisticated account. Woodward argues that the notion of 'invariant generalization' or 'change-relating generalization' can circumvent many of the problems involved in claims about lawfulness. For Woodward, 'invariance' means that a relation between two or more variables remains stable or unchanged under changes, in both background conditions and changes ('interventions') in variables figuring in the relation itself (Woodward, 2000: 205). As a consequence, invariant

\footnotetext{
11 Isomorphism is set-theoretically defined as follows (Suppes, 1998): "A simple relation structure $(A, R)-$ with $A$ being a non-empty set, and $R$ a binary relation on this set - is 'isomorphic' to a simple relation structure $\left(A^{\prime}, R^{\prime}\right)$ if and only if there is a function $f$ such that: (i) the domain of $f$ is $A$ and the range of $f$ is $A^{\prime}$; (ii) $f$ is a one-one function, and (iii) if $x$ and $y$ are in $A$ then $x R y$ if and only if $f(x) R ' f(y)$ '".
} 
generalizations relate - like causal laws - to changes between variables, and can so serve as a principle for (derived) measurement. What distinguishes invariant, change-relating generalizations from laws, however, is not the necessity of changes of the variables participating in the relation but their domain: the range of changes over which the relation remains stable. Whereas lawfulness requires an infinite domain, invariant generalizations are a matter of degree, and typically have a far more limited domain. However, as long as the domain of the invariant generalization is wide enough for the purpose of our measurement, we can use these generalizations to derive our measures. To summarize, what matters for derived measurement is whether the relation between the variables is invariant over a wide enough range of background conditions and variations of the variables involved. That provides the isomorphic mapping between an empirical and a numerical relation structure, which the RTM requires; not the causal ordering.

Let us now analyse how this account applies to the case of measurement of the NAIRU. The Phillips curve is of crucial importance for the structural approach to measurement of the NAIRU. In his seminal article, Phillips is silent as to the nature of the empirical relationship he finds. Probably, Phillips did not consider it a structural relationship. Schwier (2000: 25) argues: "His curve was definitely not structural. It was a prediction relation - a crude one but he thought it did the job. We specifically asked about this matter of being structural, and Phillips gave us a very empathic 'no'." Soon after its appearance, however, Samuelson and Solow (1960) presented the Phillips curve as an economic policy menu according to which governments could 'trade off' unemployment for inflation. This paved the way for treating the Phillips curve as a causal, or lawlike relation, and throughout the 1960s the Phillips curve was treated as such, it was: "widely interpreted as a causal relation that offered a stable trade-off to policy makers" (Friedman, 1976: 270). In the 1960s, the relation between unemployment and inflation was widely regarded as a simple causal relation represented by the Phillips curve itself: low (that is, below-NAIRU) unemployment rates 'cause' increasing inflation. However, as is now well understood by economists, the empirical Phillips curve relation broke down, and the causal interpretation of the Phillips curve did not appear to be sustainable. The Phillips curve therefore turns out not to be a deterministic law, in the sense that increasing inflation will necessarily or reliably happen below NAIRU unemployment rates. Therefore, economists currently treat the Phillips curve as a relation without an explicit causal content. 
In the structural approach, the Phillips curve is modelled as a structural relation, which results from price and wage behaviour-setting of agents. Recall from equation (3) that the simple Phillips curve is commonly expressed as:

$$
\pi_{t}=-\beta\left(u_{t}-u^{*}\right)
$$

In this elementary form, the Phillips curve serves as an invariant regularity. The actual unemployment rate $u_{t}$ and inflation $\pi_{t}$ are independently and directly measurable. When parameter $\beta$ is taken as a system-dependant constant, an isomorphic mapping $M_{1}$ is established between phenomenon $Q$ (the NAIRU) and numbers $N$ :

$$
M_{1}: \vec{Q}_{t}=\frac{\beta_{0}+\gamma_{0}}{\beta_{1}+\gamma_{1}} \rightarrow N
$$

The same holds for mapping $M_{2}$ of the more elaborated expectations augmented Phillips curve (which follows from equation 4):

$$
M_{2}: \vec{Q}_{t}=\frac{\beta_{0}+\gamma_{0}+\left(\beta_{2}+\gamma_{2}\right) X_{t}}{\beta_{1}+\gamma_{1}} \rightarrow N
$$

Unfortunately, the structural approach to measuring the NAIRU and the interpretation of the Phillips curve as an invariant regularity encountered a number of problems. Four major problems - some of which are related - will be discussed here.

\section{Uncertainty from measurement equation}

In the late 1960s, doubts began to arise about the stability of the Phillips curve, as empirical studies revealed large degrees of variance. This became most apparent in the early 1970s, when Western economies experienced stagflation, and their Phillips curve relation shifted outward to the right. Economists considered the relation between unemployment and inflation still invariant, but not stable; that is, subject to shifts over time as a result of influences yet to be determined. Finally economists became convinced that there was not just one invariant Phillips relation, but that, as a result of the shifts over time, a whole series of short-run Phillips curves could exist, each one lying closer to or further from the origin. Econometricians' usual response to this kind of problem in structural modelling is 
by 'making' the relation stable by including additional, presumably causal, variables into the specification, in order to account for the shifts. For this reason, the regressors $X_{1 t}$ and $X_{2 t}$ enter into the wage- and price- setting equations (conform equation 6 and 7), and through time, variables such as import prices, capacity utilization rate, growth rate of unit labour costs, current profit to sales ratio, etc., have been included in the wage- and pricesetting equations. A serious epistemological problem arises here, since we do not know which model for determining the NAIRU is the 'true' one. Alternative specifications are arguably equally plausible but lead to substantially different measures for the NAIRU. Most imprecision in the measurement of the NAIRU arises from this type of uncertainty (Staiger et al., 1997a), which cannot be incorporated in any confidence interval. It does not question the magnitude of parameters, but the definition of operational key variables. Consequently, as Setterfield et al. (1992: 119) argue: "The estimates of the NAIRU depend heavily on the specification of the estimated equations, the operational definition of key variables, and the data sample period". For the Phillips curve to be an invariant regularity implies that we do know that we have the 'right' isomorphic structure from which to derive our measures. Needless to say, we do not know this, a problem that causes serious problems for any measuring device.

\section{Identification problem of the measurement equation}

In the structural approach to measurement of the NAIRU, an identification problem arises. This means, in short, that the system of equations (equations 5 and 6) contains more variables than equations, which renders the parameters of the set of equations as unknown. This is particularly the case for the wage-setting equation (equation 6$).{ }^{12}$ The implications are that the wage-setting curve is unknown, and hence the NAIRU. For measurement of the NAIRU, the identification problem is solved as follows. It is assumed that the firms are on the labour demand curve (price-setting curve) and, by adding arbitrary exclusion restrictions and/or ad hoc dynamics, the parameters of the model can be identified.

Solving the identification problem and identifying the parameters is thus ultimately only possible by making arbitrary assumptions. In the words of Manning (1993): "In practice, identification is achieved by arbitrary exclusion restriction (..) and/or ad hoc dynamics. There is a certain act of faith in assuming that one gets sensible results from such practices.

\footnotetext{
${ }^{12}$ As shown above, it became standard practice in modelling this equation, to include two vectors; one vector $X_{I t}$ for controlling productivity-related variables, and one vector $X_{2 t}$ for labour market efficiency related variables.
} 
But many researchers would argue that unless additional ad hoc assumptions are imposed on the wage-setting process, these problems of identification are unavoidable".

\section{Variability of the NAIRU}

Identification of parameters became, in addition, very difficult because the NAIRU itself is time-varying. This variability makes econometric estimations of Phillips curves difficult. In the econometric literature, this problem is referred to as the "simultaneity problem" and "lagged endogeneity". The simultaneity problem exists because of what is called a feedback mechanism: inflation affects wage growth, which feeds back on inflation, ad infinitum. Simultaneity makes it difficult to evaluate the coefficients linking wage growth and inflation. Lagged endogeneity refers to the fact that current wage inflation is determined in part by its own past values. This presents certain technical complications in the estimation process, because it is difficult to determine how much of the current value of wage growth depends on past wages and how much depends on other factors such as unemployment or inflation.

As a consequence of the difficulty of identifying parameters, the $95 \%$ confidence interval for all computations covers a very wide interval for the NAIRU, usually somewhere between 4 percent and 8 percent. Staiger et al. (1997b: 34) ague: "The most striking feature of these estimates is their lack of precision. For example, the 95 percent confidence interval for the current value of the NAIRU based on the GDP deflator is 4.3 percent to 7.3 percent. In fact, our 95 percent confidence intervals for the NAIRU are commonly so wide that the unemployment [of the USA] has only been below them for a brief periods over the last 20 years." Other studies find similar wide confidence intervals. This empirical problem arises from not knowing the parameters of the model concerned. A wide range of values is consistent with the empirical evidence.

\section{$4 \quad$ Role of economic policy}

Though the exact cause or causes of the instability of the Phillips curve are not yet fully understood, the fact that the Phillips curve is also used as an important instrument of economic policy certainly adds to the instability of the curve. Phillips curves closer to the origin are taken to represent more efficient labour markets. More efficient and transparent labour markets make it easier for firms to recruit new workers, and the bidding-up process that leads to a wage-price spiral will tend to start at lower unemployment rates. A more flexible and transparent labour market will therefore lead to a low combination of 
unemployment and inflation. For this reason, governments are eager to 'shift the Phillips curve inwards deliberately' by policies aiming at more efficient matching of supply and demand for labour. However, this contributes to the instability of the Phillips curve, and makes it a flawed device for measurement. This problem is well known in economics, and is sometimes referred to as "Goodhart's law". ${ }^{13}$ It states that "any observed statistical regularity will tend to collapse once pressure is placed upon it for control purposes" (Goodhart, 1984: 96). Hoskin (1996) restated Goodhart's "law" as: "When a measure becomes a target, it ceases to be a good measure". So, either we can use the Phillips curve as an invariant regularity for measurement, or we it can use as an instrument for economic policy, but we cannot have it both ways.

To round up, in principle the Phillips curve could be explored as an invariant regularity for measurement, and the structural approach tries to do so. The major problem this approach encounters, however seems, to be the epistemological problem of finding the right specification of the Phillips curve. Rather than the simple and unique mapping

$$
M_{1}: \vec{Q}_{t}=\frac{\beta_{0}+\gamma_{0}}{\beta_{1}+\gamma_{1}} \rightarrow N
$$

we are dealing with the more complex mapping

$$
M_{2}: \vec{Q}_{t}=\frac{\beta_{0}+\gamma_{0}+\left(\beta_{2}+\gamma_{2}\right) X_{t}}{\beta_{1}+\gamma_{1}} \rightarrow N
$$

where $X_{t}$ represents the whole, unknown array of possible variables that could account for the shifts of the Phillips curve: causal variables, policy changes, shocks, etc. This leaves us with two consequences. First, we have the problem of picking the 'right' invariant regularity, as this case leaves us with multiple empirical structures that can bring about mappings between number and the phenomenon. In principle, multiple mappings should not be a problem for measurement as transformations of structures, and hence transformations of scales, are permissible. In this case, however, we are not sure which empirical structure captures the phenomenon in the first place. And even worse, we are unsure how the multiple empirical structures relate to one other. We end up with multiple empirical relational forms for the same phenomenon, without the ability to establish unique

${ }^{13}$ Named after Chief Adviser to the Bank of England, Charles Goodhart. 
isomorphic mappings and the relation between these mappings. Needless to say, this violates the uniqueness condition. Secondly, the other side of the coin is that the phenomenon of the NAIRU appears does not appear to be as well defined as we might think, as it leaves space for all sorts of variables to enter into the analysis, a point also indicated by the recent amendments to the concept of the NAIRU.

\section{$5 \quad$ The statistical approach: Vector Auto Regression models}

The second approach to measurement of the NAIRU started to gain influence in the 1980s. This approach involves the use of purely statistical methods like VAR (Vector Auto Regression) models, filters, such as the Hodrick-Prescott filter and band pass filters, or random walk models. We will focus here on Vector Auto Regression (VAR) models, as they seem most frequently applied for the measurement of the NAIRU. The econometric methodology of this approach was developed by Christopher Sims. Sims (1980) argues that the theoretical restrictions imposed on structural simultaneous models (in the tradition of the Cowles Commission), which are necessary for the identification of such models, are "incredible". In response to the "Lucas critique", and the lack of success of large structural equation models in the 1950s and 1960s, Sims suggests the use of a multivariate, autoregressive moving average model. Variables are modelled as vectors and describe the variable dynamics from their own history. In contrast with the Cowles Commission approach, in VAR models there is no a priori division of the variables into endogenous or exogenous and no a priori restrictions for identification are imposed on the variables. This means that all variables, including lagged variables, are considered endogenous and an unrestricted (by theory) VAR model regresses each (non-lagged) variable on a small set of (current and lagged) variables. As a consequence of the refusal to specify exogenous and endogenous variables, and so to specify an a priori causal structure in the model, it has been argued that VAR models are 'atheoretical macroeconometrics' (Cooley and Leroy, 1985)..$^{14}$

Let us have a closer look at Sims econometric methodology. A formal treatment of VAR models is presented in Appendix A of this paper. Less formally, we can summarize Sims methodology as follows (Pagan, 1987:15-19, and similarly Canova (1995:61)):

\footnotetext{
${ }^{14}$ Cooley and LeRoy (1985) argue in their critique of VAR models that such models do not put economic theories to the test, that the mathematics of VAR models is clear but their economic interpretation is not, and that VAR models are not useful for ex post policy analysis. They see limited use for VAR models as a tool in ex ante policy forecasts and data description.
} 
(i) Decide which variables should enter the model and transform the data to such a form that a VAR can be fitted to it;

(ii) Choose as large a number of lagged variables that is compatible with the size of the data set available, and then fit the resulting VAR;

(iii) Try to simplify the VAR by reducing the number of lags, or by imposing some arbitrary 'smoothness' restrictions upon the coefficients;

(iv) Use the orthogonized innovations [the unexpected part of the variables or disturbances] representations to address the questions of interest.

Step (i) includes setting up the VAR model for the desired purpose, from an unrestricted (by theory) structural model (similar to equation 19: see Appendix A), while step (ii) decides the number of lags $p$. The number of lags is usually determined by a statistical selection criterion such as Akaike or Schwarz Information Criterion in order to find a balance between overparametization and oversimplification of the model. Next, it is assumed that the VAR model is hit by shocks (innovations), which serve as the input of the linear dynamic system. In order to do this, we need the Moving Average (MA) representation of the VAR. This can be obtained by application of Wold's decomposition theorem. ${ }^{15}$ This theorem states that any zero mean, covariance stationary process can be represented as a moving average sum of a deterministic constant (or a constant plus trend), which is a function of time $t$, and white noise processes which are temporal, cyclical deviations from the trend. Provided the Wold has zero mean covariance and the weights $A_{1}^{i}$ of the error term $e_{t}$ are square summable we can formally represent the decomposition theorem as: ${ }^{16}$

$$
x_{t}=\mu+\sum_{i=0}^{\infty} A_{1}^{i} e_{t-i}
$$

where $\mu$ represents a deterministic constant or a constant plus trend (for the vector $x_{t}$ ), and $\sum_{i=0}^{\infty} A_{1}^{i} e_{t-i}$ the white noise process which is considered to represent the temporal, cyclical

\footnotetext{
${ }^{15}$ Herman Wold (1908-1992) was a Swedish statistician who worked mainly on time-series analysis. He disagreed with Haavelmo's probability approach, and suggested the use of recursive causal chain models. His decomposition theorem followed from his $\mathrm{PhD}$ thesis.

${ }^{16}$ See, for example, Greene, 2003: 619.
} 
deviations from the trend. The coefficients of matrix $A_{1}^{i}$ are called the impulse response coefficients associated with the innovations (shocks) $e_{t}$. They describe the propagation of the shocks through the model, and the final effect of the shocks on $x_{t}$. For the measurement of the NAIRU, the important assumption is thus made that the actual unemployment rate can be split up, according to Wold's decomposition theorem, into a trend $\mu$ (the NAIRU) and the cyclical component $\sum_{i=0}^{\infty} A_{1}^{i} e_{t-i}$ ('unemployment gap'), written as:

$$
u_{t}=\mu \text { (the NAIRU) } \quad+\quad \sum_{i=0}^{\infty} A_{1}^{i} e_{t-i} \text { ('unemployment gap'). }
$$

The unobservable level around which the actual unemployment rate fluctuates is now regarded as the NAIRU, and the NAIRU and 'unemployment gap' are assumed to be uncorrelated. The next steps involve the identification of the shocks (step iii), and the interpretation of the shock impulse response function (step iv).

There are a number of ways to achieve identification. Sims proceeds by analysing the moving average representation of a system with orthogonalized innovations (step iv). This means that the error covariance matrix is diagonalized by multiplying the moving average representation of the VAR by a unique triangular matrix with units (1's) on the main diagonal. This approach to identification is known as a Choleski decomposition. An alternative way to achieve identification (step iv) is to use the Blanchard-Quay decomposition (Blanchard and Quah, 1989). ${ }^{17}$ Since this latter approach to identification is often used for the measurement of the NAIRU, and in addition, is more intuitive to the reader, we will leave Sims approach here (step iv) and now follow the Blanchard-Quah approach instead. In the Blanchard-Quay decomposition a Wold decomposition is applied, but, for identification, restrictions are imposed on the coefficients of the VAR by using some specific economic theory of long-run neutrality of one variable on another (here money on employment). ${ }^{18}$ The shocks are taken as being transitory. The long-run effects, and hence the long-run dynamics of the VAR model, are then known and used for

\footnotetext{
17 Blanchard and Quah apply their model to GNP and unemployment, and their model is used for the determination of potential output and the 'output gap'. In recent years, the Blanchard-Quah model was modified for measurement of the NAIRU.

${ }^{18}$ Since this step requires specific economic, causal assertions (in a similar way as the Cowles Commission structural approach), Blanchard-Quah type autoregression models are considered as Structural VAR (SVAR) models.
} 
restricting the coefficients of the model. Conversely, sometimes the short-run dynamics are known and not the long run outcome. In that case, we could use knowledge about the shortrun behaviour for imposing restrictions on the coefficients.

Finally, the NAIRU is identified as the part of unemployment, which is inflationneutral in the long run. That is, the gap disturbance $\left(e_{t}\right)$ has no impact on the NAIRU in the long run. Therefore, the NAIRU is identified by setting the temporary component of $u_{t}$ (the 'unemployment gap') to zero, $\sum_{i=0}^{\infty} A_{1}^{i} e_{t-i}=0$. The NAIRU is thus operationally defined as the component of the actual unemployment rate that is uncorrelated to inflation in the long run, and the Wold decomposition theorem provides the measuring instrument that, applied to the VAR, turns that set of equations into a measuring instrument for the NAIRU. ${ }^{19}$

\section{The relational structure in VAR models}

Defining the empirical relational structure in the VAR model is not immediately straightforward. VAR modellers explicitly reject the view that we know, a priori, the causal relations needed for measurement, so instead, they aim to use the statistical relations uncovered by the VAR procedure to determine statistically-defined causal relations. Since the VAR model runs regressions on past values of variables, they rather exploit conditional correlations, which are identified with the statistically-defined Granger-causal ordering. A variable $x$ Granger-cause $y$ (denoted as $x \rightarrow y$ ) if: "present $y$ can be predicted with better accuracy by using past values of $x$ rather than by not doing so, other information being identical" (Charemza and Deadman, 1992: 190). ${ }^{20}$ So, a weak form of causation - Granger causation - is applied in the VAR model. However, in Sims methodology the test of Granger-causality is only relevant for verifying endogeneity or exogeneity after the model is already constructed, and Sims takes it that Granger non-causality verifies strict exogeneity. All variables in the VAR model are endogenous, but not in the sense of the

\footnotetext{
${ }^{19}$ This statistical approach is applied for the measurement of the NRU too. Since the NRU is constant in the short term and independent of inflation, we can decompose unemployment according to the Wold theorem into the NRU and an unemployment gap, and run an autoregression on unemployment data alone.

${ }^{20}$ We speak of Granger causation if the addition of information X (at time t-1) to the set of all past and present information $U_{\mathrm{t}-1}$ (at time $\mathrm{t}-1$ ) leads to a reduction of the mean square error (MSE) of the unbiased prediction $\tilde{y}_{t}$. Thus formally there is Granger-causality if: $\operatorname{MSE}\left(\tilde{y}_{t} \mid \mathrm{U}_{\mathrm{t}-1}\right)<\operatorname{MSE}\left(\tilde{y}_{t} \mid \mathrm{U}_{\mathrm{t}-1} \backslash \mathrm{X}_{\mathrm{t}-1}\right)$, where MSE stands for the mean square error of predicting $\tilde{y}_{t}$ conditional on information set $U_{\mathrm{t}-1}$ (Charemza and Deadman, 1992: 191).
} 
Cowles Commission who stick to the traditional, Humean interpretation of causality. In Sims methodology, VAR models are essentially correlations, and so is the empirical structure upon which measurement of the NAIRU rests. Though the original VAR specification was deliberately atheoretical, economic theory cannot be eschewed completely. Economic theory enters in the analysis of the shock impulse response function and the variance decomposition. Economic theory tells us, for example, that real (unemployment) shocks will affect inflation in the long run, but not the other way around. ${ }^{21}$ In the end, the economist imposes a causal structure upon the otherwise correlational structure of the estimated VAR in order to interpret it.

The Moving Average representation of the VAR, which was obtained by the application of the Wold theorem, forms the direct mapping of the phenomenon - the NAIRU - with numbers. The isomorphic mapping of this case of measurement $\left(M_{3}\right)$ therefore looks like this:

$$
M_{3}: \vec{Q}_{t}=\mu+\sum_{i=0}^{\infty} A_{1}^{i} e_{t-i} \rightarrow N
$$

\section{$7 \quad$ Conclusions}

Measurement is about bringing about a correspondence between phenomena and numbers. Campbell (1928) and Woodward (2000) provide an account how invariant regularities can do so. Various types of regularities can be used: causal relations, correlations, identies, etc, as long as the physical relation can be expressed in a mathematical relation and is invariant over a wide range of background conditions and changes in the variables figuring in the relation.

The concept of the NAIRU appeared to be a clearly-defined theoretical concept when it was first introduced. The problem was only finding a satisfactory measurement procedure for it. Two approaches to the measurement of the NAIRU can be distinguished: a structural approach and a statistical approach. Both approaches derive measures of the NAIRU from an apparent invariant regularity, though they both employ a slightly different method for deriving their numbers.

\footnotetext{
${ }^{21}$ In addition, Cooley and LeRoy (1985) argue that orthogonal innovations need to be treated as exogenous variables. This requires imposition of a prior causal structure upon the system in a similar fashion as the Cowles Commission methodology (see also Qin, 2006).
} 
The structural approach explores a causal strategy, and tries to capture causal determinants of NAIRU. It models the wage bargaining process that underlies the Phillips curve. For a long time, this unemployment-inflation relation was considered as a causal relation, and causal relations could be used satisfactory for providing an isomorphic structure. However, this structural approach, though still most often used, is not fully satisfactory from a measurement perspective. The main problem concerns the identification of the Phillips curve, and hence the establishment of a strict isomorphic mapping. The contemporary interpretation is that the Phillips curve represents an unstable relationship and is therefore unsuitable to serve as a measuring instrument of the NAIRU. This is not quite right, as it is not the instability itself that creates the problem. In the case of a perfectly stable Phillips curve, the NAIRU would be a constant variable (see Figure 4b).

(a)

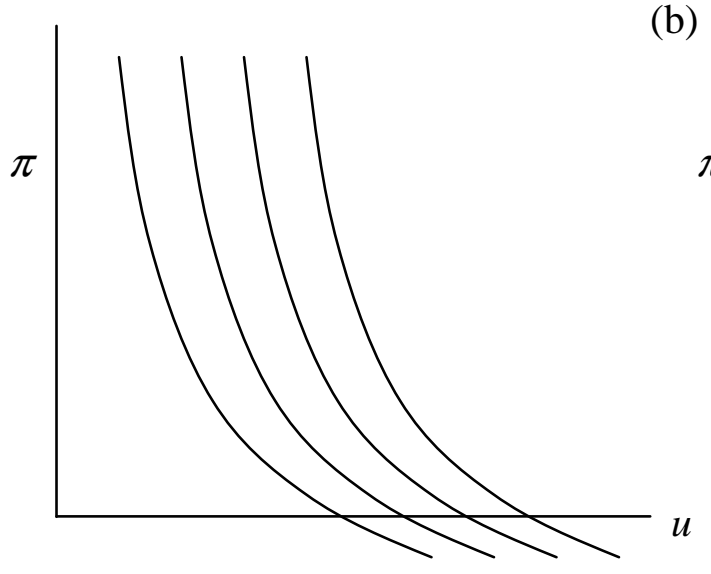

Instability of the Phillips curve Variability of the NAIRU (b)

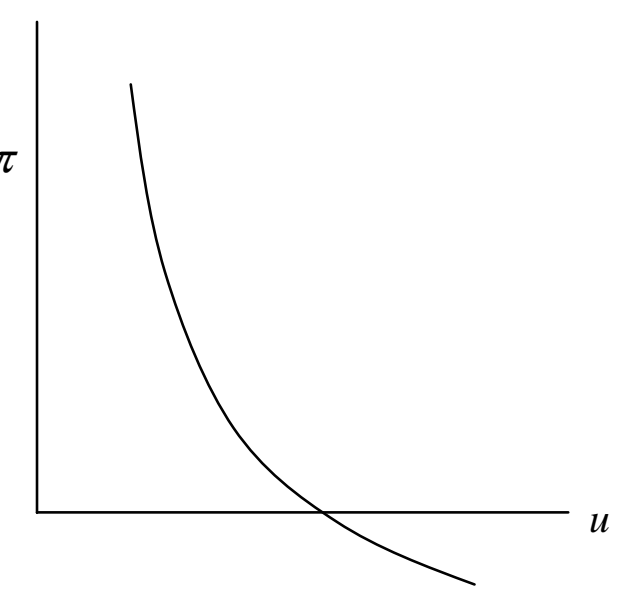

Stability of the Phillips curve Invariability of the NAIRU

Figure 4: Consequences of interpretations of the Phillips curve for measurement of the NAIRU

However, since the NAIRU is not constant but a time-varying concept, it will be clear that there will a whole set of Phillips curves, that necessarily moves along with the NAIRU. Without movements of the Phillips curve the variability of the phenomenon could not be captured. The real problem is that the exact shape of the Phillips curve cannot be identified, and it is therefore not possible to make a clear distinction between the variability of the Phillips curve and the variability of the NAIRU. 
The inability to identify the exact shape of the Phillips curve gives rise to great variability of NIARU values and wide reliability intervals. For this purpose, economists have tried to deal with the instability of the Phillips curve by adding explanatory variables into the Phillips curve equation in order to 'make' the Phillips curve stable and so rescue the causal measurement strategy. However, this did not yield the desired result. And since economic theory is not able to provide exclusive information about the causal factors involved, a multitude of alternative, equally plausible specifications exists in the structural approach literature, and therefore we end up with multiple mappings for the measurement of a phenomenon. However, in this case, multiple mappings do not follow from uncertainty at a conceptual level of the measurand, but do we find multiple empirical, relational forms.

Given the these problems, it is no surprise to see that the statistical approach is gaining popularity, as it circumvents many of the problems inherent to the structural approach. The statistical approach is thus an attractive alternative to the problems of structural modelling and eschews the search for simple structure. In addition, non-structural methods require fewer assumptions than structural methods, and are therefore to be preferred from a modelling point of view. In the statistical approach, measurement of the NAIRU is based on correlation. The variable of interest is derived from an autoregression on past values of inflation and unemployment. Measurement of the NAIRU in the statistical approach is thus, in essence, based on exploring a correlation. It differs however greatly from, say a thermometer where an observable (expansion of mercury) 'stand-in' for a correlated unobservable (heat) in order to measure the correlated unobservable (heat) indirectly. VAR models do not rely on a representative or stand-in, but the unobservable variable of interest - the NAIRU - is measured more or less 'directly' from an autoregression. Measures of the NAIRU are derived as in the structural approach, though not from a causal relation but from a correlation, which is exploited as an invariant regularity.

VAR models came under fire in the mid 1980s by supporters of the Cowles Commission approach, and were criticized for being 'atheoretical macroeconometrics' for several reasons, the most important being that the interpretations of the dynamic behaviour are faulty and that for identification ad hoc dynamics are imposed. This criticism of VAR models echoes the sort of criticism that Burns and Mitchell received in the 1930s concerning their work on the measurement of business cycles, which, as Koopmans put it in his classical 1947 article, was "measurement without theory". Cooley and LeRoy foresee only limited use of VAR models, precisely because they are largely unrelated to economic 
theory. The only benefit from VAR models seems to be their ability to discover statistical correlations in economic data. Nevertheless, it is precisely this feature of VAR models summarizing correlations in data - that makes them a useful foundation for the construction of measuring instruments. The application of the Wold decomposition theorem to the correlations in data found by VAR models could, provided the relations are stable, well be used as a principle to bring about a correspondence between unobservable and 'more observable' data. The fact that the correlations may not be interesting for economists, or lack an economic underpinning, is not relevant from the perspective of measurement. What matters is that the correspondence they bring about is stable (Chao 2002; Boumans 2005) and, as such, they can function well as an invariant regularity for derived measurement.

\section{Appendix A VAR models: A formal treatment ${ }^{22}$}

\section{Main idea:}

The NAIRU can be measured by decomposing unemployment in two parts. One is the NAIRU and the other the 'unemployment gap' (gap between actual unemployment and the NAIRU). Two disturbances are assumed to affect fluctuations in unemployment: the NAIRU disturbance and the gap disturbance. In this approach the NAIRU is defined as the part of unemployment that is inflation neutral in the long run. It is mathematically derived by setting the long-run effect of the gap disturbance on the NAIRU to zero.

\section{Formal treatment:}

VAR models and structural models have a similar structure. Let $\pi$ be inflation, $u$ unemployment, $b$ and $v$ coefficients, and $\varepsilon$ an error term. The unrestricted, structural VAR alternative to the unrestricted structural equations model of the type:

$$
\begin{aligned}
& u_{t}=b_{10}+b_{12} \pi_{t}+v_{11} u_{t-1}+v_{12} \pi_{t-1}+\varepsilon_{u t} \\
& \pi_{t}=b_{20}+b_{21} u_{t}+v_{21} u_{t-1}+v_{22} \pi_{t-1}+\varepsilon_{\pi t}
\end{aligned}
$$

can, by using matrix algebra, be described as:

${ }^{22}$ This section is loosely based on Enders (2004: 264 -306). 


$$
\left[\begin{array}{cc}
1 & b_{12} \\
b_{21} & 1
\end{array}\right]\left[\begin{array}{l}
u_{t} \\
\pi_{t}
\end{array}\right]=\left[\begin{array}{l}
b_{10} \\
b_{20}
\end{array}\right]+\left[\begin{array}{ll}
v_{11} & v_{12} \\
v_{21} & v_{22}
\end{array}\right]\left[\begin{array}{l}
u_{t-1} \\
\pi_{t-1}
\end{array}\right]+\left[\begin{array}{l}
\varepsilon_{u t} \\
\varepsilon_{\pi t}
\end{array}\right]
$$

or

$$
B x_{t}=C_{0}+C_{1} x_{t-1}+\varepsilon_{t},
$$

where: $\quad B=\left[\begin{array}{cc}1 & b_{12} \\ b_{21} & 1\end{array}\right] \quad x_{t}=\left[\begin{array}{l}u_{t} \\ \pi_{t}\end{array}\right] \quad C_{0}=\left[\begin{array}{l}b_{10} \\ b_{20}\end{array}\right] \quad C_{1}=\left[\begin{array}{ll}v_{11} & v_{12} \\ v_{21} & v_{22}\end{array}\right] \quad \varepsilon_{t}=\left[\begin{array}{l}\varepsilon_{u t} \\ \varepsilon_{\pi t}\end{array}\right]$.

Multiplying both sides by matrix $B^{-1}$ yields the standard form (reduced form) of the VAR as:

$$
x_{t}=A_{0}+A_{1} x_{t-1}+e_{t},
$$

where: $A_{0}=B^{-1} C_{0}$

$$
\begin{gathered}
A_{1}=B^{-1} C_{1} \\
e_{t}=B^{-1} \varepsilon_{t} .
\end{gathered}
$$

VAR models concentrate on shocks and therefore we need to identify the relevant shocks so that we can compute the impulse response function. If the first-order autoregressive model (equation 18) is stable (that is, the value of $A_{1}$ lies inside the unit circle), and the reduced-form residual vector $\varepsilon_{t}$ is normally independently distributed with the variancecovariance matrix $\Sigma$, we can apply the Wold decomposition theorem (see also Section 5, equation 13). That makes it possible to invert the VAR model (equation 19) into a Moving Average (MA) form:

$$
\begin{aligned}
x_{t} & =A_{0}+A_{1}\left(A_{0}+A_{1} x_{t-2}+e_{t-1}\right)+e_{t} \\
& =\left(I+A_{1}\right) A_{0}+A_{1}^{2} x_{t-2}+A_{1} e_{t-1}+e_{t},
\end{aligned}
$$

where $I=2 \times 2$ identity matrix. After $n$ iterations, this yields:

$$
x_{t}=\left(I+A_{1}+\ldots+A_{1}^{n}\right) A_{0}+\sum_{i=0}^{n} A_{1}^{i} e_{t-i}+A_{1}^{n+1} x_{t-n-1}
$$

which can be reduced to: 


$$
x_{t}=\mu+\sum_{i=0}^{\infty} A_{1}^{i} e_{t-i},
$$

where $\mu$ represents a deterministic constant or a constant plus trend (for the vector $x_{t}$ ), and $\sum_{i=0}^{\infty} A_{1}^{i} e_{t-i}$ the temporal, cyclical deviation from the trend. Equation (20) is known as the Moving Average representation of the VAR. The coefficients of matrix $A_{1}^{i}$ are called the impulse response coefficients associated with the innovations $e_{t}$. They describe the propagation of the shocks through the model and the final effect of the shocks on $x_{t}$. Both $\pi$ and $u$ can thus, according to the Wold theorem, be decomposed into temporary and permanent components. Applying this Wold decomposition theorem to the vector $x_{t}$ then yields the following equations for $\pi$ and $u$ :

$u_{t}=\mu_{u}$ (the NAIRU) $\quad+\quad \sum_{i=0}^{\infty} A_{12}^{i} e_{t-i}$ (the 'unemployment gap')

and $\pi_{t}=\mu_{\pi}$ ('core-inflation') $+\sum_{i=0}^{\infty} A_{22}^{i} e_{t-i}$ (temporary deviation).

The permanent component of unemployment is the NAIRU, while the permanent component of inflation is referred to as 'core-inflation'. ${ }^{23}$ Blanchard and Quay (1989) apply the Wold decomposition and use long-run neutrality assumptions for identification. ${ }^{24}$ The NAIRU is identified as the part of unemployment which is inflation neutral in the long run. That is, the gap disturbance $\left(e_{t}\right)$ has no impact on the NAIRU in the long run. Therefore, the NAIRU is identified by setting the temporary component of $u_{t}$ (the "unemployment gap') to zero, $\sum_{i=0}^{\infty} A_{1}^{i} e_{t-i}=0$.

\footnotetext{
${ }^{23}$ Danny Quah (1995), for example, defines 'core inflation' as "that component of measured inflation that has no medium- to long-run impact on real output".

${ }^{24}$ In contrast with Christopher Sims (1980), who uses the moving average representation of a system with orthogonalized innovations.
} 


\section{References}

Blanchard, O. J., and Quah, D. (1989), The Dynamic Effects of Aggregate Demand and Supply Disturbances, The American Economic Review, vol. 79, no. 4, 655-673

Boumans, M. (2005), How Economists model the World into Numbers, Routledge, London

Campbell, N.R. (1928), Measurement and Calculation, An Account of the Principles of, Longmans, Green and Co. Ltd., London

Canova, F. (1995), The Economics of VAR models, in: Hoover, K. (ed.), Macroeconometrics; Developments, Tensions and Prospects, Kluwer Academic Publishers

Chao, H.K. (2002), Representation and Structure; The Methodology of Econometric Models of Consumption, Tinbergen Institute $\mathrm{PhD}$ thesis, no. 289, Amsterdam

Charemza, W.W. and Deadman, D.F. (1992), New Directions in Econometric Practice, Edward Elgar, Cheltenham

Cooley, T.F. and LeRoy, S.F. (1985), Atheoretical Macroeconomics; A Critique, Journal of Monetary Economics, vol. 16, no. 3, 283-308

Cross, R. (ed). (1995), The Natural Rate of Unemployment; Reflections on 25 Years of the Hypothesis, Cambridge University Press, Cambridge

Ellis, B. (1966), Basic Concepts of Measurement, Cambridge University Press, Cambridge

Enders, W. (2004), Applied Econometric Time Series, John Wiley \& sons, Inc., Hobroken

Friedman, M. (1968), The Role of Monetary Policy, American Economic Review, March, no.1

Friedman, M. (1975), Unemployment versus Inflation; An evaluation of the Phillips curve, The Institute of Economic Affairs

Friedman, M. (1976), Inflation and Unemployment, Nobel Memorial Lecture, University of Chicago, Illinois, December 13

Goodheart, C.A.E. (1984), Monetary Theory and Practice; The UK Experience, Macmillan Press, London

Greene, W. H. (2003), Econometric Analysis, Prentice Hall, New Jersey

Hoskin, K. (1996), The 'Awful Idea of Accountability': Inscribing People into the Measurement of Objects, in Munro, R. and Mouritsen, J. (eds.), Accountability: Power, Ethos and the Technologies of Managing, International Thomson Business Press, London, 265-282.

Koopmans, Tj. (1947), Measurement without Theory, Review of Economics and Statistics, vol. 29, 161-179 
Layard, R., Nickell, S. and Jackman, R. (1991), Unemployment: Macroeconomic Performance and the Labour Market, Oxford University Press, Oxford

Manning, A (1993), Wage Bargaining and the Phillips Curve: The Identification and Specification of Aggregate Wage Equations, The Economic Journal, vol. 103, no. 416, 98-118

Mitchell, W. and Muysken, J. (2003), Misrepresentation and Fudge - The OECD NAIRU Consensus, Centre for Full Employment and Equity, Working Paper no. 03-11

Modiglianin, F. and Papademos, L. (1975), Monetary Policy for the Coming Quarters: The Conflicting Views, The New England Review, March- April, 2-35. Reprinted in: The Collected Papers of Franco Modigliani, (1980), vol. 3, MIT Press, Cambridge

Morgan, M.S. (2001), Making Measurement Instruments, In: Klein, J.L. and Morgan, M.S. (eds.), The Age of Economic Measurement, Annual Supplement to Volume 33, History of Political Economy, Duke University Press, Durham and London

Pagan, A. (1987), Three Econometric Methodologies: A Critical Appraisal, Journal of Economic Surveys, vol. 1, 3-24

Phelps, E. S.(1967), Phillips Curves, Expectations of Inflation, and Optimal Unemployment over Time, Economica, vol. 34, no. 135, 254-81

Phillips, A.W. (1958), The Relation between Unemployment and the Rate of Change of Money Wage Rates in the United Kingdom, 1861-1957, Economica, vol. 25, no. 100, 283-299

Qin, D. (2006), VAR Modelling Approach and Cowles Commission Heritage, Queen Mary University of London working paper, no. 557

Quah, D.T. and Vahey, S.P. (1995), Measuring Core Inflation, The Economic Journal, vol. 105, no. $432,1130-1144$

Richardson, P., Boone, L., Giorno, C. et. al. (2000), The Concept, Policy use and Measurement of Structural Unemployment: Estimating a Time Varying NAIRU across 21 OECD Countries, OECD economic department working paper no. 250, OECD, Paris, France

Rodenburg, P. (2006), The Construction of Instruments for Measuring Unemployment, Tinbergen Institute PhD thesis no. 383, Amsterdam

Samuelson, P.A. and Solow, R.M. (1960) Analytical Aspects of Anti-Inflation Policy, American Economic Review, vol. 50, no. 2, Papers and Proceedings of the Seventy-second Annual Meeting of the American Economic Association. (May, 1960), 177-194.

Schwier, A. (2000), Playing around with some Data, in: Leeson, R. (ed.) A.W.H. Phillips: Collected Works in Contemporary Perspective, Cambridge University Press, Cambridge

Setterfield, M.A., et. al., L. (1992), Searching for a Will o' the Wisp: an empirical study of the NAIRU in Canada", European Economic Review, vol. 36, no. 1, 119-136

Sims, C.A. (1980), Macroeconomics and Reality, Econometrica, vol. 48, no. 1, 1-48 
Staiger, D., Stock, J.H. and Watson, M.W. (1997a), How precise are Estimates of the Natural Rate of Unemployment? In: Romer, C.D. and Romer, D.H. (eds.), Reducing Inflation: Motivation and Strategy, NBER, University of Chicago Press, Chicago

Staiger, D., Stock, J.H. and Watson, M.W. (1997b), The NAIRU, Unemployment and Monetary Policy, Journal of Economic Perspectives, vol. 11, no. 1, 33-49

Suppes. P. (1998), Theory of Measurement, in: Edward Craig (Ed), Routledge Encyclopedia of Philosophy, Routledge

Tobin, J. (1980), Stabilization Policy Ten Years after, Brookings Papers on Economic Activity, No. 1, 19-71

Tobin, J. (1997), Supply Constraints on Employment and Output: NAIRU versus Natural Rate, Cowles Foundation Paper 1150, Yale University, New Haven

Woodward, J. (2000), Explanation and Invariance in the Special Sciences, British Journal for the Philosophy of Science, vol. 51, no. 2, 197-254

Wulwick, N.J. (1989), Phillips' Approximate Regression, Oxford Economics Papers, new series, vol. 41, no. 1, 170-188 